\title{
USE OF HYBRID CLASSROOM AND OPEN EDUCATIONAL RESOURCES: EXPERIENCE GAINED FROM A UNIVERSITY IN HONG KONG
}

\author{
Nikolina Dragicevic, Ioanna Pavlidou and Eric Tsui \\ The Hong Kong Polytechnic University, Hung Hom, Kowloon, Hong Kong SAR
}

\begin{abstract}
Hybrid classroom, which combines face-to-face and online learning, is becoming a popular way of delivering courses in higher education and a subject of growing interest in academic literature. At the same time, the ongoing development of digital educational resources and a trend of openness in systems and education gives open educational resources an increasingly important role in democratising learning. The purpose of this study is to present the approach that combines hybrid classroom and open educational resources developed at one higher education institution in Hong Kong and to investigate the students' views towards the approach. A questionnaire inquiring students' affection towards hybrid classroom and open educational resources has been administered to postgraduate students of the knowledge management programme and related critical factors have been identified and discussed. Results show that the adopted approach enriches students' learning experience by providing a variety of benefits, such as allowing diverse methods and modes of delivery and enabling more flexible, self-controlled, and self-paced learning. Particularly promising seems to be the positive experience from joining the co-located and distance learners, with providing potential advantages such as cross-cultural learning. Moreover, students reported that their learning experience was enhanced with open educational resources. However, some challenges, of technical and pedagogical nature, have been identified, which require further considerations of curriculum design to facilitate hybrid classroom (and use of open education resources) optimally.
\end{abstract}

\section{KEYWORDS}

Hybrid Classroom, Open Educational Resources, Higher Education, Hybrid Learning

\section{INTRODUCTION}

The development of information and communication technologies generated digital affordances that allowed organising, sharing and storing knowledge online and streaming high-quality media that can efficiently simulate the physical environment. At the same time, the pervasiveness of digital devices used in workplaces and daily lives and the ubiquity of data created the need to develop a set of digital competences such as learning in networks, learning from diversified media sources and leveraging on technologies (e.g., Gallardo-Echenique et al., 2015; Germaine et al., 2016; Muller, 2015; Siemens, 2008). The availability of technological resources and the necessities of this rapidly changing world require to revisit teaching and learning in education.

For these reasons, in recent years, there has been an emergence of a variety of new pedagogies that incorporate digital technologies and online learning (Bower et al., 2017; Kemp and Grieve, 2014). Within these approaches, classrooms are not bounded by walls but can extend to virtual environments, giving rise to the hybrid classrooms $(\mathrm{HC})$, i.e., the considerate symbiosis of the face-to-face (F2F) and online learning experiences (Bersin, 2004). Technology also provides an opportunity to make education more open, such as to share knowledge and learning materials in a digital format, giving prominence to open educational resources (OER), i.e., freely available digital resources (D'Antoni, 2009).

In this paper, building on these trends in higher education and practice, we present our approach that combined HC and OER in knowledge management (KM) postgraduate courses at The Hong Kong Polytechnic University (PolyU) and report students' attitudes towards hybrid learning and using open resources in learning.

There are two main research objectives for this study:

1) To ascertain how HC and OER are used in one higher education institution in Hong Kong;

2) To understand students' affection towards the use of HC and OER. 
To answer these questions, first, in section 2, we provide a short theoretical background on the concepts of HC and OER. Then, in section 3, we introduce the approach that is used at the postgraduate academic programme. Next, in section 4, we report and discuss the results from the questionnaire inquiring students' inclination towards joining F2F and online learning environment and using OER in comparison to traditional textbooks. Last, in section 5, we conclude with some implications for further research.

\section{THEORETICAL BACKGROUND}

\subsection{Hybrid Classroom - Definition and Types}

$\mathrm{HC}$ is a type of course that combines the traditional face-to-face (F2F) learning with online (web-based) learning. Online learning can be synchronous, as in the case of live lectures, or asynchronous, as in the case of pre-recorded lectures and presentations with voice. Apart from online lectures, it can consist of other online methods and tools, such as online teaching materials, online pre-lecture assignments and discussion forums (Zhao and Breslow, 2013). "Hybrid" as a term is many times used interchangeably with "blended", in most studies having identical meaning (Zhao and Breslow, 2013). In this sense, a course is hybrid or blended when F2F learning is supplemented by web-based facilitation of delivering the lecture (and not merely supported by digital means such as computers or presentation tools) (Helms, 2014; Zhao and Breslow, 2013). Such an understanding of $\mathrm{HC}$, where $\mathrm{F} 2 \mathrm{~F}$ is combined with the online lectures, we also adopt in this paper.

Zhao and Breslow (2013) classify HC according to the degree of usage of online learning: replacement model, where a portion of the F2F lectures is reduced and replaced by online learning; supplemental model, where the number of $\mathrm{F} 2 \mathrm{~F}$ classes remains the same, but the students are recommended to engage in online learning; emporium model, where the courses are delivered exclusively online but with access to a physical learning and resource centre; and, last, the buffet model, that offers all the options of F2F and online learning and every student can create a personalised combination on their individual taste. Other scholars attempted to categorise hybrid classrooms by suggesting the exact portion of online learning that is adopted. For example, Allen et al. (2007) propose that boundaries of the online part of the course are between 30-79\%; a lower percentage would be considered as a web-facilitated course and a higher as a fully online course.

\subsection{Applications of Hybrid Classroom}

At the practical level, there can be numerous combinations and applications of HC. A few examples include a classroom that consists of only distant students connected in a virtual environment, only co-located students or a mix of both (Bower et al., 2017). The technologies reported in the literature are also diverse, from online chat, live video, quizzes and breakout rooms to blended reality with 3D media (Bower et al., 2017).

One of the benefits of $\mathrm{HC}$ is in breaking the classroom boundaries which allows a broader students' participation, such as of disengaged university students, individuals that have big distance from the institution and vulnerable groups (Bower et al., 2015; Bowyer and Chambers, 2017). HC also creates a significant opportunity to enrich the learning experience. For example, the formation of an educational ground that is diverse in activities, experiences or even cultures, as it can occur in a cross-institutional $\mathrm{HC}$, has a potential to satisfy the needs of different learner's personalities (Picciano, 2009), enhance interest and healthy competition (Bower et al., 2015; Milheim, 2014), stimulate critical thinking (Loes et al., 2012) and support the development of working skills for diverse teams (Gomez et al., 2009).

\subsection{Open Educational Resources}

OER is a term related to a broader set of entities, processes and systems that are based on openness, depicted by the concepts such as open-source, open access, open data, open innovation and open government. The first definition of OER was coined by UNESCO (2002) as "The open provision of educational resources, enabled by information and communication technologies, for consultation, use and adaptation by a community of users for non-commercial purposes." According to Smith and Seward (2017), this openness has three dimensions: production, distribution and consumption. In this sense, OER can be described as a result of open, collaborative production of people who are willing to add value; as a product of open distribution, since they are located in 
the public domain and not channelled to the users by traditional commercial distribution channels; and as a learning resource available for open consumption, as anyone can access and enjoy their value.

With the developments of information and communication technologies, on the one hand, and a need for the democratisation of knowledge, on the other, the use of OER becomes more and more important in educational environment (D'Antoni, 2009). OER materials can be used for teaching, learning, assessment and research purposes as well as for curriculum development. Some of the benefits include access to cost-free materials, the flexibility to combine different resources, use of diversified resources, control over which resource(s) to use (Wiley et al., 2014).

Most of the research focuses on identifying the impact directly on students' performance, such as GPA, engagement or assessment scores (Hilton, 2016), while several scholars studied the perceptions from teacher's perspective in using them (Pitt, 2015).

\section{DESCRIPTION OF THE APPROACH}

This paper describes an approach that combines HC and OER in the quest to equip students with digital competences at the KM programme at PolyU. Both HC and OER are implemented in the context of the open pedagogy tendencies of the PolyU, characterised by the learner centricity, knowledge sharing, technology enablement, connectedness and openness of resources (Figure 1).

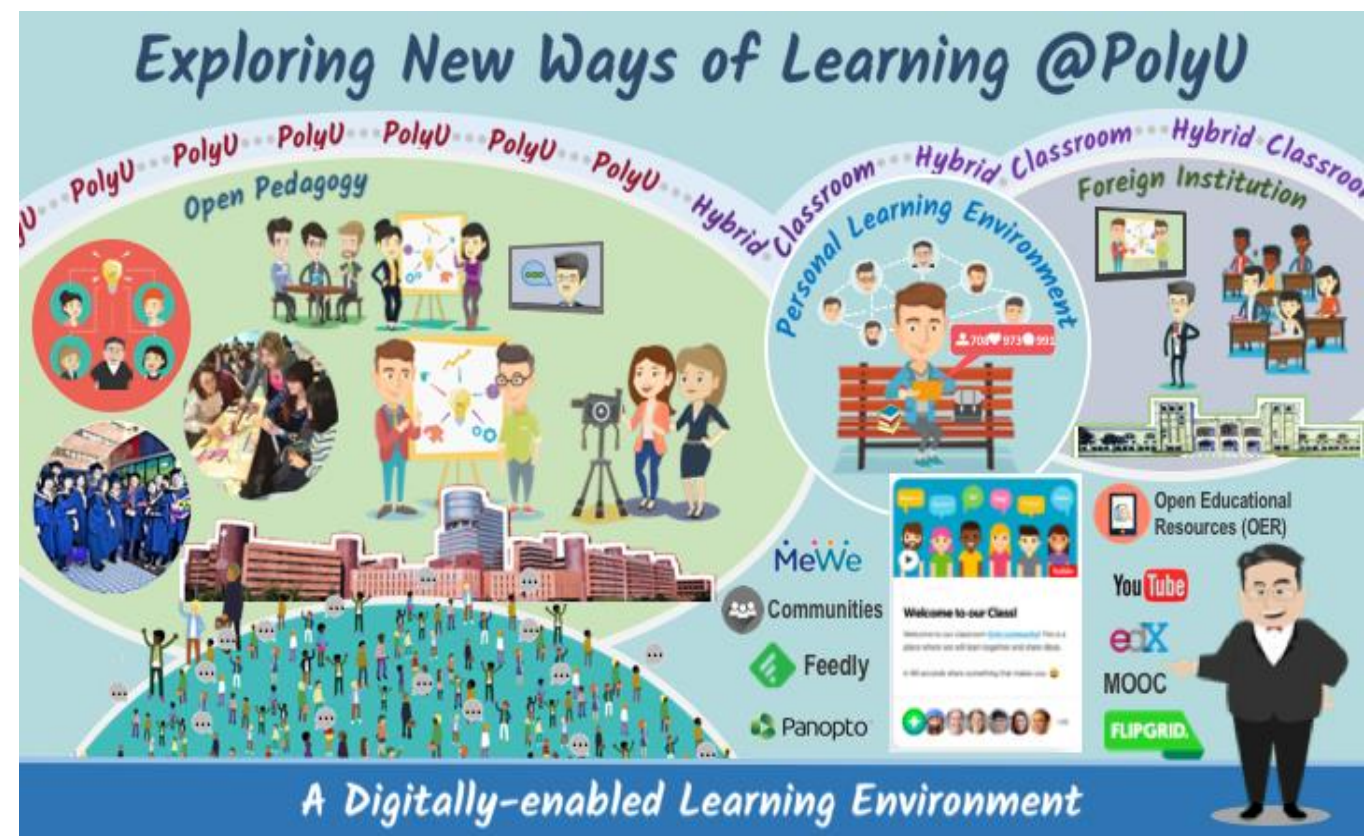

Figure 1. Hybrid classroom and OER are adopted in line with the open pedagogy tendencies at PolyU

Table 1 provides a summary of ways hybrid classroom is utilised at the KM programme at PolyU. In its simplest form, a subject teacher, apart from F2F conducts some of the classes online (typically around 30\%), consistent with the replacement model of HC (Zhao and Breslow, 2013).

The approach also allows more complex forms, such as a collaboration between host university and universities from abroad. In the latter case, for example, the teacher would set up an online class where he would co-lecture with his/her colleague from other university and invite students from both universities to participate and collaborate via Blackboard collaborate (or potentially other platforms). Since the subject teacher of the KM programme is a leader of the two Massive Open Online Courses (MOOCs) (edX, 2020), MOOC learners are also invited to join the online classrooms when the topic is suitable. 
Enactment of $\mathrm{HC}$ consists of two components. One is a personal learning environment and network (PLE\&N) which refers to the peer-based learner-centric platform and online discussion forum set up by a teacher, which aims to foster self-regulated, network-based, and lifelong learning (Tsang and Tsui, 2017). For organising HC, a MeWe community platform is used, and relevant articles are automatically located and sent to the students, members of the forum. Students review, discuss and further annotate these articles.

Table 1. Types of HC used at KM programme at PolyU

\begin{tabular}{|c|c|c|c|c|c|c|}
\hline \multirow{2}{*}{$\begin{array}{l}\text { Types of } \\
\text { hybrid } \\
\text { classrooms }\end{array}$} & \multirow[t]{2}{*}{ Facilitator(s) } & \multirow{2}{*}{$\begin{array}{l}\text { Style of } \\
\text { interaction } \\
\text { (Online/ } \\
\text { F2F/ } \\
\text { Both) } \\
\end{array}$} & \multirow[b]{2}{*}{$\begin{array}{l}\text { Mode of } \\
\text { interaction } \\
\text { (Synchronous/ } \\
\text { Asynchronous/ } \\
\text { Both) } \\
\end{array}$} & \multicolumn{3}{|c|}{ Attendees and mode of attendance } \\
\hline & & & & PolyU students & $\begin{array}{l}\text { Students from } \\
\text { an overseas } \\
\text { university }\end{array}$ & $\begin{array}{l}\text { MOOC } \\
\text { learners }\end{array}$ \\
\hline Basic & PolyU staff & $\begin{array}{l}\text { F2F } \\
\text { classroom } \\
(70 \%) ; \\
\text { online } \\
\text { environment } \\
(30 \%)\end{array}$ & Both & $\begin{array}{l}\text { Yes } \\
\text { Co-located } \\
\text { (PolyU } \\
\text { classroom) and } \\
\text { remotely }\end{array}$ & No & $\begin{array}{l}\text { When a } \\
\text { suitable } \\
\text { topic } \\
\text { Remotely }\end{array}$ \\
\hline Extended & $\begin{array}{l}\text { PolyU staff } \\
\text { Guest lecturer }\end{array}$ & $\begin{array}{l}\text { F2F class + } \\
\text { real-time } \\
\text { Q\&A over } \\
\text { the online } \\
\text { platform }\end{array}$ & Both & $\begin{array}{l}\text { Yes } \\
\text { Co-located } \\
\text { (PolyU } \\
\text { classroom) and } \\
\text { remotely }\end{array}$ & No & $\begin{array}{l}\text { When a } \\
\text { suitable } \\
\text { topic } \\
\text { Remotely }\end{array}$ \\
\hline \multirow[t]{2}{*}{ Linked } & $\begin{array}{l}\text { PolyU staff }+ \\
\text { staff from a } \\
\text { different } \\
\text { institution }\end{array}$ & $\begin{array}{l}\text { Each } \\
\text { facilitator } \\
\text { takes a turn } \\
\text { to present; } \\
\text { students } \\
\text { from both } \\
\text { sides ask } \\
\text { questions }\end{array}$ & Both & $\begin{array}{l}\text { Yes } \\
\text { Co-located } \\
\text { (PolyU } \\
\text { Classroom) and } \\
\text { using the online } \\
\text { platform during } \\
\text { F2F }\end{array}$ & $\begin{array}{l}\text { Yes } \\
\text { Co-located } \\
\text { (Home } \\
\text { institution's } \\
\text { classroom) and } \\
\text { using the online } \\
\text { platform during } \\
\text { F2F }\end{array}$ & $\begin{array}{l}\text { When a } \\
\text { suitable } \\
\text { topic } \\
\text { Remotely }\end{array}$ \\
\hline & $\begin{array}{l}\text { PolyU staff + } \\
\text { staff from a } \\
\text { different } \\
\text { institution }\end{array}$ & $\begin{array}{l}\text { Mini- } \\
\text { lecture, } \\
\text { Q\&A, } \\
\text { assignment, } \\
\text { mutual } \\
\text { projects etc. }\end{array}$ & Both & Remotely & Remotely & $\begin{array}{l}\text { When a } \\
\text { suitable } \\
\text { topic } \\
\text { Remotely }\end{array}$ \\
\hline
\end{tabular}




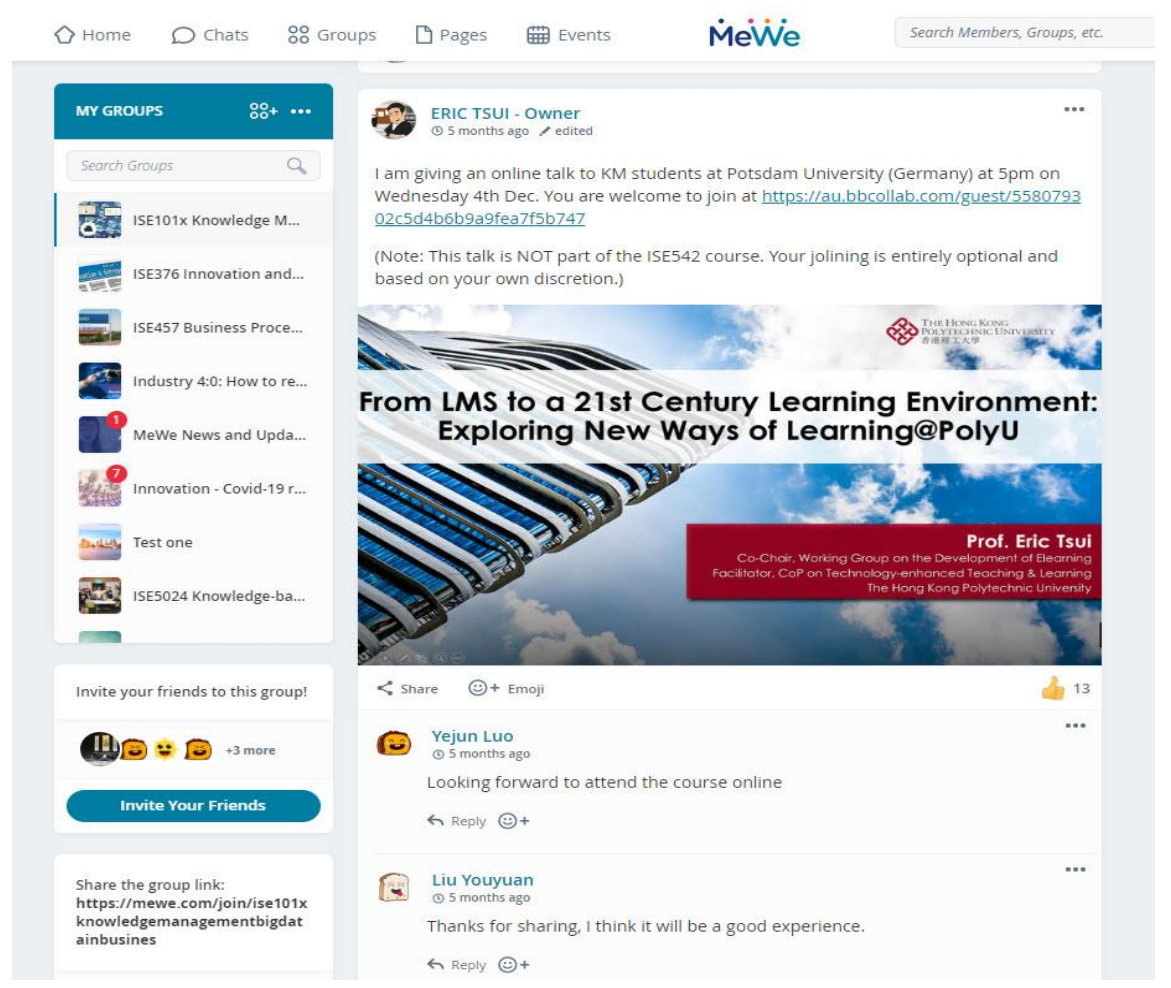

Figure 2. Using the social network of MeWe as part of the PLE\&N

The other component of $\mathrm{HC}$ is the organisation of an online classroom by using a combination of Panopto, Blackboard Collaborate, and MeWe platforms. A range of activities are designed to reflect various teaching and learning pedagogies which, among others, include: 1) teachers from different institutions presenting on a topic of common interest via live or pre-recorded sessions; 2) teachers organising joint live sessions with Q\&A; 3) students engaging in role-playing exercises and taking turns to ask and answer questions; 4) students from multiple universities engaging in common assignments; 5) students from multiple universities engaging in common projects; 6) students forming joint, multi-institutional teams to collaborate and co-produce the subject deliverables. Both synchronous and asynchronous collaborations are used since students from different institutions do not share the same class schedule or time zone.

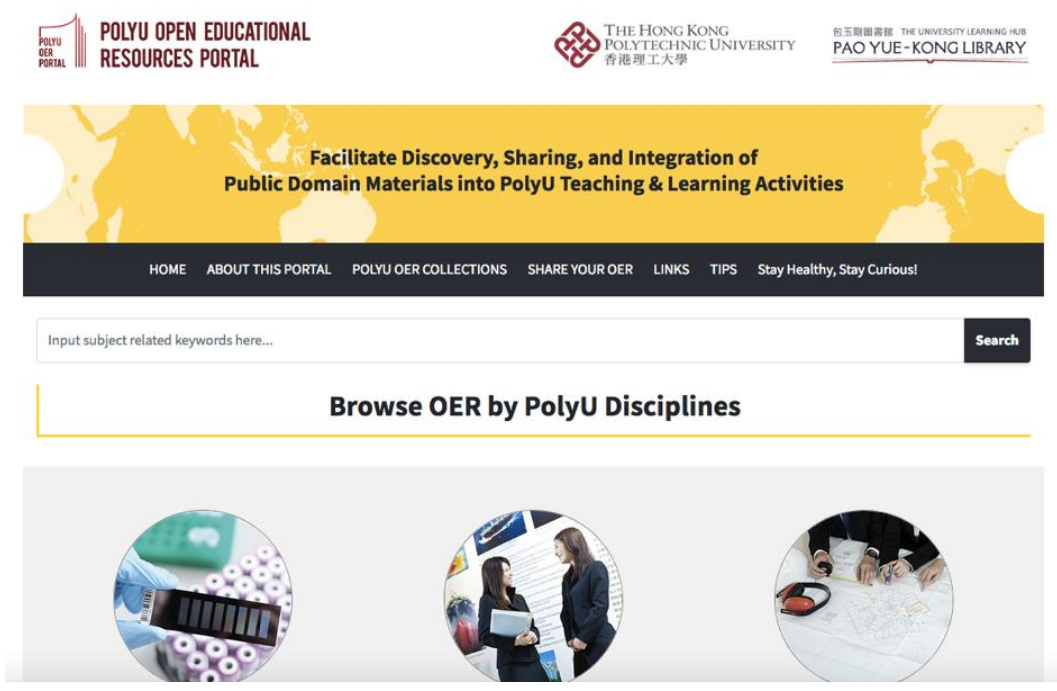

Figure 3. PolyU OER library 
An important part of $\mathrm{HC}$ is the use of OER, the purpose of which is to be a supplementary learning material to pre-designed course content. A subject teacher helps to identify relevant OER resources for his hybrid classes by working with a librarian and his students. An increasingly important role in providing resources for the enactment of HC plays the OER library (https://oer.lib.polyu.edu.hk/home.html) set up by PolyU. PolyU library endeavours both into the production of its resources and relying on the world-wide commons-based peer production model (e.g., the model used by Wikipedia) of OER (Wiley et al., 2014).

Students are also encouraged to identify, share and use relevant and good quality OERs (with a teacher's endorsement) with their peers. Teacher assesses the quality and usefulness of OER materials, which are in the form of, among others, articles and videos posted into the chosen platforms, for example, Blackboard Collaborate, MEWE community, or in PLE\&N. A subject teacher incorporates selective OER materials to update course content and informs the library to update the OER portal.

OER used for the HC purposes cover, among others, Massive Open Online Courses (MOOC), YouTube videos, MIT Open Courseware, MERLOT repository, RSS feeds, industry news and articles, industry and academic reports.

\section{METHOD}

\subsection{Participants, Data Collection and Analysis}

The 74 students who participated in the first semester of the 2019/2020 KM postgraduate course were asked to participate in the study and complete an online questionnaire about their attitude towards HC and use of OER. The final number of students who completed the survey is 40 . A questionnaire has been adapted based on Lin, (2008) and Bliss et al. (2013). HC teacher has transmitted the questionnaire in an online form. The questionnaire consists of two main components - one related to HC and the other to OER. In the HC section, students were asked to share their views and behaviours regarding computer access and their HC background, different features of the technology used, and their attitude towards the HC. In the OER section, students were asked to compare the use of OER to commonly used traditional textbooks on a variety of factors, such as cost, quality, outcomes and ways of use.

The collection and analysis of data were of qualitative and quantitative nature, consisting of multiple-choice, Likert-type, multiple-select, constructed response items, and open-ended questions that asked students about each of the themes mentioned above. Data were analysed by congruently using quantitative and qualitative procedures. Descriptive analytics were employed to analyse the data quantitively in terms of percentages. Qualitative data was analysed by using comparative method grounded theory methodology (Corbin and Strauss, 1990; Kolb, 2012), which utilises an analytic procedure of constant comparison and relies on the researchers` ability to interpret data, discover patterns in it, and create relevant themes.

\subsection{Results and Discussion}

Table 2 presents some descriptive statistics regarding the technology usage of the students and their prior experience with HC. The results regarding the first questionnaire element, which is about the devices that students use to participate in HC, shows a clear tendency in using personal mobile devices (laptop, smartphone and tablet) over desktop computers. Such finding comes in line with the current global trend of using mobile devices over computers for a growing number of tasks (Biddix et al., 2015; Dolch and Zawacki-Richter, 2018; Eurostat, 2015). At the same time, the majority of the students also show high usage of their computer with $60 \%$ exceeding the 3 hours daily. A clear preference from students to access the online delivery of the HC from home was noted $(85 \%)$, while a smaller percentage chose to join from a library or dormitory. Last, it is noteworthy to mention that the greater part of the students $(67.5 \%)$ involved in this survey has never participated in a hybrid classroom in the past. 
Table 2. Descriptive Statistics of Student Technology and HC Usage

\begin{tabular}{lc}
\hline Device Used (\%) & $\%$ \\
\hline Desktop & 12.5 \\
Laptop & 62.5 \\
Smartphone & 35 \\
Tablet & 25 \\
Other & \\
Computer Access $(\%)$ & 0 \\
\hline At computer lab & 85 \\
At home & 2.5 \\
In the dorm & 13.5 \\
In the library & 15 \\
\hline Frequency Using Computer $(\%)$ & 60 \\
\hline 3- 5 hours per week & 25 \\
Daily more than 3 hours & 0 \\
Every day 1-2 hours & 32.5 \\
Less than 1-2 hour per week & 67.5 \\
\hline Hybrid Classroom Taken $(\%)$ & \\
\hline Yes & \\
No & \\
\hline
\end{tabular}

\subsubsection{Views on Hybrid Classroom}

In the questionnaire, students were asked to reflect their affection toward $\mathrm{HC}$, and the results are depicted in Table 3 categorised in positive, negative and overall items. The discussion of the findings presented in the table incorporates the results from several open-ended questions in which the authors asked the students about their best experiences and issues or concerns they might have regarding $\mathrm{HC}$.

Overall, students expressed positive attitudes towards using $\mathrm{HC}$ and would recommend hybrid learning to friends $(47.5 \%)$.

Table 3. Student Affection Toward Hybrid Classroom

\begin{tabular}{|c|c|c|c|c|c|}
\hline \multicolumn{6}{|l|}{ Survey items } \\
\hline Positive items & 1 & 2 & 3 & 4 & 5 \\
\hline I could control the pace of my own learning & 0 & 0 & 22.5 & 50 & 27,5 \\
\hline Online assignments were helpful in understanding the course content & 5 & 5 & 27.5 & 52.5 & 10 \\
\hline The connection between what I did online and in-class was clear & 2.5 & 15 & 30 & 37.5 & 15 \\
\hline $\begin{array}{l}\text { I didn't have any difficulty in managing my time for the online part of } \\
\text { the course }\end{array}$ & 0 & 25 & 27.5 & 37.5 & 10 \\
\hline Negative items & 1 & 2 & 3 & 4 & 5 \\
\hline The online course materials were difficult to follow. & 10 & 15 & 47.5 & 27.5 & 0 \\
\hline The time I spent online would better have been spent in class. & 15 & 27.5 & 32.5 & 17.5 & 7.5 \\
\hline $\begin{array}{l}\text { I found participating in the online messaging system useless for my } \\
\text { learning. }\end{array}$ & 10 & 25 & 27.5 & 30 & 7.5 \\
\hline I was unable to share ideas with other students on a regular basis. & 7.5 & 27.5 & 35 & 25 & 5 \\
\hline Overall items & 1 & 2 & 3 & 4 & 5 \\
\hline I would recommend taking the hybrid classroom to a friend & 7.5 & 15 & 30 & 30 & 17.5 \\
\hline I would take another course that incorporates BB Collaborate & 2.5 & 15 & 37.5 & 30 & 15 \\
\hline
\end{tabular}

\section{Diverse learning approaches}

Overall, the students expressed positive attitudes towards making use of the diversity of learning methods provided by HC. Furthermore, $62 \%$ of the students found the online assignments to be helpful to understand the syllabus and $25 \%$ were confident to deal with the online materials, but $27 \%$ perceived the online materials were hard to follow. 
Nevertheless, several students reported that they found the experience of online learning useful since they got the chance to practice skills which would help them to adapt to digital working environments. This finding supports the argument that the adopted approach aids with developing digital competences in students.

\section{Self-control and self-paced learning}

$77.5 \%$ of the students reported that they felt able to learn on their own pace, and $47.5 \%$ managed their time successfully in the online activities of the course. Confirming this finding, most of the students in their open-ended comments emphasised that online classes are particularly "convenient" due to "flexible time management for having lectures" or "flexibility of time and place to study." This result is satisfactory; a student's independence and self-configuration is a critical element of a successful hybrid classroom (McGee and Reis, 2012). Furthermore, the availability of enough time within a lecture allows students to comprehend information and develop their critical views (Westermann, 2014).

\section{Connectivity and interactivity}

Some students stressed that the online interactions stimulated them to engage more; for example, one of the respondents acknowledged that "some classmates who are less active in F2F lecture are more active in an online course." Reasons for students' higher engagement could be found in the online environment-specific teaching, and learning circumstances which minimise the power distance between students and teachers and are by design more learner-centric than F2F environments (Ku and Lohr, 2003). For example, traditionally, in eastern societies, teachers exhibit a more authoritative instruction style, and students tend to save face and avoid conflict, influenced by the Confucius' philosophy (Chiu, 2009). However, online learning practices seem to mitigate some of these cultural aspects and empower students to engage without fear of negative evaluation.

The students also found value in continuing to engage in the F2F classes, particularly due to the opportunity to socialise in person with their peers and the opportunity to discuss and comprehend the ideas more deeply. F2F learning is recognised to facilitate the socialisation aspect of learning better than online learning (Bower et al., 2015).

\section{Technology and structure}

Most of the students (45\%) expressed satisfaction from using the online teaching system BB Collaborate, although they did not find as useful its online messaging system. The students also mentioned that few technological challenges, such as audio and video quality and usage - disconnectedness, interruptions, and distortions, undermined the flow of the lecture.

Regarding the pedagogical challenges, the students emphasised that some of the learning materials were not adjusted appropriately for the online presentation and that it was hard to follow the content. Some of the students also stressed that they would favour more structured peer-to-peer interactions in the online classroom and that it was hard for them to keep concentration and attention online. $30 \%$ of the students reported that it was difficult to share ideas in HC setting with their peers. Nevertheless, a significant percentage of students felt that there was a clear connection between what they have learned in the physical and online classroom $(52.5 \%)$ and would not change the online part of the course for a physical classroom (42.5\%).

Table 4. Students' affection towards the participation of another university

\begin{tabular}{lc}
\hline Participation of the faculty from a third party institution adds value to a class & $\%$ \\
\hline Significant value & 27.5 \\
Good value & 52.5 \\
Medium value & 20 \\
Little value-added & 0 \\
No value-added & 0 \\
\hline Participation of the students from a third party institution adds value to a class \\
\hline Significant value & 22.5 \\
Good value & 47.5 \\
Medium value & 30 \\
Little value-added & 0 \\
No value-added & 0 \\
\hline
\end{tabular}


Lastly, as shown in Table 4, the students highly valued the interaction and communication with international students and faculty, with most of the students reporting that they were of good or significant value. In the open-ended questions, they stressed that they had enjoyed the opportunity to "communicate with Professor far from Hong Kong," "sharing the knowledge," and "interaction with foreign scholars."

These results come in line with prior research which reports about the positive benefits of joining the remote and co-located students is $\mathrm{HC}$, such as the exposure to different teaching and learning styles of the participants from the guest institution (Milheim, 2014).

\subsubsection{Views on Open Educational Resources}

Within the framework of $\mathrm{HC}$ and curriculum expansion, OER were used as a supplementary learning material to traditional textbooks. Table 5 shows that most of the students used OER resources or 2-3 times a month $(35 \%)$ or $2-3$ times a week $(27.5 \%)$.

Table 5. Descriptive statistics on OER usage

\begin{tabular}{lc}
\hline Frequency of using OER & $\%$ \\
\hline Never & 0 \\
$2-3$ times a semester & 25 \\
$2-3$ times a month & 35 \\
$2-3$ times a week & 27.5 \\
Daily & 12.5 \\
\hline
\end{tabular}

We have further asked students to reflect their experience in using OER in terms of perceived quality and perceived usefulness for learning, the results of which are shown in Table 6 and Table 7, respectively. In general, OER are assessed as having a similar quality to the traditional textbooks (77.5\%), with a significant percentage of students finding them better (15\%) and a smaller part finding them worse than the textbooks (7.5\%). This finding comes in line with prior research that explores students impressions of OER having comparable or better quality than textbooks (Watson et al., 2017).

Noteworthy is the finding that the majority of students (75\%) think that OER and public internet articles have about the same quality, while $15 \%$ find OER better and only $2.5 \%$ worse than internet articles. More studies are required to understand whether such results correspond to the objective value of the two types of resources, or they arise from students' inability to appraise and compare the two critically.

A high percentage of the participants (37.5\%) assesses textbooks cost as too excessive, the majority (45\%) has a neutral opinion, and $17 \%$ think that the cost is not "too much". Commercial textbooks cost is broadly accepted both by students and institutions as an essential downside and as a significant factor for the adoption of OER in higher education (Hilton, 2016; McGreal, 2019).

Table 6. Students perceptions of the quality of OER

\begin{tabular}{lc}
\hline Overall, what do you think of the OER materials used in this course? & $\%$ \\
\hline Worse than the quality of the traditional textbooks & 7.5 \\
About the same as the quality of the traditional textbooks & 77.5 \\
Better than the quality of the traditional textbooks & 15 \\
\hline How do you rate the quality of the OER materials adopted in this course in relation & $\%$ \\
to public internet articles? & 2.5 \\
\hline Worse than the quality of the public internet articles & 75 \\
About the same as the quality of the public internet articles & 22.5 \\
Better than the quality of the public internet articles & $\%$ \\
\hline In general, textbooks and course materials cost too much & 10 \\
\hline Strongly disagree & 7.5 \\
Disagree & 45 \\
Neither agree nor disagree & 20 \\
Agree & 17.5
\end{tabular}


At the same time, the vast majority of students regards that OER indeed improves their learning experience from moderate $(65 \%)$ to high $(7.5 \%)$ degree. In comparison, $10 \%$ finds OER did not contribute at all and $10 \%$ that even decreased their learning experience. Only a small part of the course audience ( $7.5 \%$ of students) did not perceive any connection of OER to their learning experience.

Table 7. Students perceptions on the usefulness of OER for learning

\begin{tabular}{lc}
\hline How do you rate the quality of the OER materials adopted in this course in relation & $\%$ \\
to traditional textbooks? & 10 \\
\hline OER materials were detrimental to my learning experience & 10 \\
OER materials did not enhance my learning experience at all & 7.5 \\
OER materials have not been used for my learning experience & 65 \\
OER materials have mildly enhanced my learning experience & 7.5 \\
OER materials have greatly enhanced my learning experience & 10 \\
\hline Imagine you have the freedom to choose one out of two courses with the same syllabus (one course & $\%$ \\
uses OER materials, and the other one uses traditional published textbook(s), what would be your \\
likely decision?
\end{tabular}

\section{CONCLUSION}

In this paper, we have presented the approach that combines HC and OER and applied it in a postgraduate course at the Hong Kong Polytechnic University. We have distributed a questionnaire to capture the students' affection towards HC and OER. The data analysis helped us to understand the advantages, challenges and possible future studies.

Consistent with the previous studies, the students' overall attitude towards HC is positive (Bower et al., 2015; Lin, 2008; Zydney et al., 2019). Most of the students thought that HC enriches their learning experience by providing a variety of benefits, such as the utilisation of diverse methods and modes of delivery, more flexible, self-controlled, and self-paced learning. Particularly promising seems to be the positive experience from joining the co-located and distance learners, with providing potential advantages such as cross-cultural learning. Future larger-scale studies (employing rigorous methods of investigation) would need to be deployed to explore the particulars of the online interactions (e.g., differences in learning styles in different cultures) among the co-located and distance learners, to understand and facilitate their learning in HC in optimal ways. The role of domain, cultural or other types of diversity in cross-institutional hybrid classrooms and how it affects students' satisfaction, interest and engagement, performance, needs to be investigated.

Apart from the diverse benefits, enacting HC brings also diverse challenges that lie in the technological and pedagogical dimensions (Raes et al., 2019). The technological challenges stem from the audio and video disruptions. The pedagogical challenges emerge from the issues regarding the redesigning traditional lectures in a hybrid context, creating a continuum between the F2F and online learning and providing an inclusive and engaging experience for remote users by facilitating at the same time a connection between the F2F and the remote participants (Bower et al., 2017; Gomez et al., 2009).

Most of the students reported that their learning experience was enhanced with OER, and in general, provided positive attitudes to using OER in comparison to traditional textbooks and internet resources. The study on the benefits of OER in HC is, however, very limited in scope. Further studies are required which would investigate whether students` contributions in the learning assignments were generated by using OER as references and to which extent they contributed to students' comprehension of the subject topic.

Overall, consistent with the previous studies, our research shows that the experience of students is not undermined through teaching but is mainly influenced by the content and the quality of the teaching itself (Aly, 2013; Nortvig et al., 2018). However, the experience of the students' that join the online classroom from different physical locations might be different than in the traditional, F2F classroom (Raes et al., 2019; Szeto, 2014; Zydney et al., 2019). Consecutively, HC cannot be based on the adjusted curriculum of a traditional classroom but need to be designed from scratch, a recommendation that is widely accepted in the literature (e.g., Bowyer and Chambers, 2017). To facilitate HC optimally, a further investigation of different curriculum designs, practices and experiences becomes vital. 


\section{ACKNOWLEDGEMENT}

The work covered in this paper is funded by a Teaching and Development Grant (Project code: GYF18-19/PT1/ISE01) by The Hong Kong Polytechnic University. Support by the university is gratefully acknowledged.

\section{REFERENCES}

Allen, I.E., Seaman, J., Garrett, R., 2007. Blending in: The Extent and Promise of Blended Education in the United States, Sloan Consortium (NJ1). Sloan Consortium.

Aly, I., 2013. Performance in an Online Introductory Course in a Hybrid Classroom Setting. Canadian Journal of Higher Education 43, 85-99.

Bersin, J., 2004. The blended learning book: Best practices, proven methodologies, and lessons learned. John Wiley \& Sons.

Biddix, J.P., Chung, C.J., Park, H.W., 2015. The hybrid shift: Evidencing a student-driven restructuring of the college classroom. Computers \& Education 80, 162-175. https://doi.org/10.1016/j.compedu.2014.08.016

Bliss, T., Robinson, T.J., Hilton, J., Wiley, D.A., 2013. An OER COUP: College Teacher and Student Perceptions of Open Educational Resources. JIME 2013, 4. https://doi.org/10.5334/2013-04

Bower, M., Dalgarno, B., Kennedy, G.E., Lee, M.J.W., Kenney, J., 2015. Design and implementation factors in blended synchronous learning environments: Outcomes from a cross-case analysis. Computers \& Education 86, 1-17. https://doi.org/10.1016/j.compedu.2015.03.006

Bower, M., Lee, M.J.W., Dalgarno, B., 2017. Collaborative learning across physical and virtual worlds: Factors supporting and constraining learners in a blended reality environment. British Journal of Educational Technology 48, 407-430. https://doi.org/10.1111/bjet.12435

Bowyer, J., Chambers, L.C., 2017. Evaluating blended learning: Bringing the elements together. Cambridge Assessment, Research Matters.

Chiu, Y.-C.J., 2009. Facilitating Asian students' critical thinking in online discussions. British Journal of Educational Technology 40, 42-57. https://doi.org/10.1111/j.1467-8535.2008.00898.x

Corbin, J., Strauss, A., 1990. Grounded theory research: Procedures, canons and evaluative criteria. Zeitschrift für Soziologie 19, 418-427.

D’Antoni, S., 2009. Open Educational Resources: reviewing initiatives and issues. Open Learning: The Journal of Open, Distance and e-Learning 24, 3-10. https://doi.org/10.1080/02680510802625443

Dolch, C., Zawacki-Richter, O., 2018. Are students getting used to Learning Technology? Changing media usage patterns of traditional and non-traditional students in higher education. Research in Learning Technology 26. https://doi.org/10.25304/rlt.v26.2038

edX, 2020. Eric Tsui [WWW Document]. edX. URL https://www.edx.org/bio/eric-tsui (accessed 5.1.20).

Eurostat, 2015. Being young in Europe today - 2015 edition.

Gallardo-Echenique, E.E., de Oliveira, J.M., Marqués-Molias, L., Esteve-Mon, F., 2015. Digital Competence in the Knowledge Society 11, 17.

Germaine, R., Richards, J., Koeller, M., Schubert-Irastorza, C., 2016. Purposeful Use of 21st Century Skills in Higher Education. Journal of Research in Innovative Teaching 9.

Gomez, E.A., Dezhi Wu, Passerini, K., 2009. Traditional, Hybrid and Online Teamwork: Lessons from the Field. Communications of the Association for Information Systems 25, 395-411. https://doi.org/10.17705/1CAIS.02533

Helms, S.A., 2014. Blended/hybrid courses: a review of the literature and recommendations for instructional designers and educators. Interactive Learning Environments 22, 804-810. https://doi.org/10.1080/10494820.2012.745420

Hilton, J., 2016. Open educational resources and college textbook choices: a review of research on efficacy and perceptions. Education Tech Research Dev 64, 573-590. https://doi.org/10.1007/s11423-016-9434-9

Kemp, N., Grieve, R., 2014. Face-to-face or face-to-screen? Undergraduates' opinions and test performance in classroom vs online learning. Front Psychol 5. https://doi.org/10.3389/fpsyg.2014.01278

Kolb, S.M., 2012. Grounded theory and the constant comparative method: Valid research strategies for educators. Journal of emerging trends in educational research and policy studies 3, 83-86.

Ku, H.-Y., Lohr, L.L., 2003. A case study of Chinese student's attitudes toward their first online learning experience. ETR\&D 51, 95-102. https://doi.org/10.1007/BF02504557 
Lin, Q., 2008. Student Views of Hybrid Learning: A One-Year Exploratory Study. Journal of Computing in Teacher Education 10.

Loes, C., Pascarella, E., Umbach, P., 2012. Effects of Diversity Experiences on Critical Thinking Skills: Who Benefits? The Journal of Higher Education 83, 1-25.

McGee, P., Reis, A., 2012. Blended Course Design: A Synthesis of Best Practices. Journal of Asynchronous Learning Networks 16, 7-22.

McGreal, R., 2019. A Survey of OER Implementations in 13 Higher Education Institutions. The International Review of Research in Open and Distributed Learning 20, 141-145. https://doi.org/10.19173/irrodl.v20i5.4577

Milheim, K.L., 2014. Facilitation Across Cultures in the Online Classroom. International Journal of Learning, Teaching and Educational Research 5.

Muller, J., 2015. The future of knowledge and skills in science and technology higher education. High Educ 70, 409-416. https://doi.org/10.1007/s10734-014-9842-x

Nortvig, A.-M., Petersen, A.K., Balle, S.H., 2018. A Literature Review of the Factors Influencing E-Learning and Blended Learning in Relation to Learning Outcome, Student Satisfaction and Engagement. Electronic Journal of e-Learning 16, $46-55$.

Picciano, A.G., 2009. Blending with Purpose: The Multimodal Model. Journal of Asynchronous Learning Networks 13, $7-18$.

Pitt, R., 2015. Mainstreaming Open Textbooks: Educator Perspectives on the Impact of OpenStax College open textbooks. The International Review of Research in Open and Distributed Learning 16. https://doi.org/10.19173/irrodl.v16i4.2381

Raes, A., Detienne, L., Windey, I., Depaepe, F., 2019. A systematic literature review on synchronous hybrid learning: gaps identified. Learning Environ Res. https://doi.org/10.1007/s10984-019-09303-Z

Siemens, G., 2008. Learning and knowing in networks: Changing roles for educators and designers. ITFORUM for Discussion 27, 1-26.

Smith, M., Seward, R., 2017. Openness as Social Praxis. First Monday 22. https://doi.org/10.5210/fm.v22i4.7073

Tsang, H.W.C., Tsui, E., 2017. Conceptual design and empirical study of a personal learning environment and network (PLE\&N) to support peer-based social and lifelong learning. VINE Journal of Information and Knowledge Management Systems 47, 228-249. https://doi.org/10.1108/VJIKMS-03-2017-0010

UNESCO, 2002. Forum on the Impact of Open Courseware for Higher Education in Developing Countries, UNESCO, Paris, 1-3 July 2002: final report - UNESCO Digital Library [WWW Document]. URL https://unesdoc.unesco.org/ark:/48223/pf0000128515 (accessed 5.1.20).

Watson, C.E., Domizi, D.P., Clouser, S.A., 2017. Student and Faculty Perceptions of OpenStax in High Enrollment Courses. International Review of Research in Open and Distributed Learning 18, 287-304.

Westermann, E.B., 2014. A Half-Flipped Classroom or an Alternative Approach?: Primary Sources and Blended Learning. Educational Research Quarterly 38, 43-57.

Wiley, D., Bliss, T.J., McEwen, M., 2014. Open Educational Resources: A Review of the Literature, in: Spector, J.M., Merrill, M.D., Elen, J., Bishop, M.J. (Eds.), Handbook of Research on Educational Communications and Technology. Springer, New York, NY, pp. 781-789. https://doi.org/10.1007/978-1-4614-3185-5_63

Zhao, Y., Breslow, L., 2013. Literature Review on Hybrid/Blended Learning.

Zydney, J.M., McKimmy, P., Lindberg, R., Schmidt, M., 2019. Here or There Instruction: Lessons Learned in Implementing Innovative Approaches to Blended Synchronous Learning. TechTrends 63, 123-132. https://doi.org/10.1007/s11528-018-0344-z 